\section{Commentary on ASI Profile of Persons who Re-enter Treatment for Substance Use Disorders}

Received: August 28, 2017; Accepted: September 24, 2017; Published: September 30, 2017

\section{Introduction}

Is the clinical profile of persons with multiple treatment reentries different from that of the persons who come in treatment for the first time? In order to provide valuable information for treatment and policy purposes, it is important to know how client admission profiles differ as a function of treatment history. Simoneau and Brochu [1] in their article entitled Addiction severity index profile of persons who reenter treatment for substance use disorders discuss this important issue.

\section{Background}

Despite a growing interest in persons with multiple treatment reentries, few studies have defined their clinical profile. The aim of this study was to compare the severity profile of substance use disorder and related problems of persons who reenter treatment to the profile of those who come in for treatment for the first time.

\section{Methods}

A data bank containing 6,651 Addiction Severity Index (ASI) interviews from three rehabilitation centers was used for the analyses.

\section{Results}

All the ASI composite scores were significantly higher among persons who reentered treatment than among those who came for the first time.

\section{Discussion and Conclusion}

The results support the hypothesis of a more severe ASI profile and substance use-related problems among persons who reenter treatment compared to those who come for the first time. Consequently, they have greater needs, and the treatment offered should be adjusted accordingly.

This topic is important because it involves many people. In the United States as well as in the province of Quebec, Canada, over $50 \%$ of the persons admitted to public treatment system have already received treatment. Despite the prolonged adverse reenter treatment.

\section{Hélène Simoneau* \\ Département des sciences de la santé communautaire, Université de Sherbrooke, Canada}

*Corresponding author: Hélène Simoneau

helene.simoneau.cdc@ssss.gouv.qc.ca

Professeure associée, Département des sciences de la santé communautaire, Université de Sherbrooke, Centre de réadaptation en dépendance de MontréalInstitut universitaire, Centre intégré de Santé et de services sociaux du Centre-Sudde-l'lle-de-Montréal 950 rue de Louvain est, Montréal, Qc. H2M 2E8, Canada

Tel: (514)-385-5728

Citation: Perry C (2017) Commentary on ASI Profile of Persons who Re-enter Treatment for Substance Use Disorders. J Drug Abuse Vol.3 No.3:24

consequences associated with addiction, there is no consensus about the nature of care or treatment modalities that should be offered to these individuals. The results of the Simoneau and Brochu's [1] study provide empirical data to feed the debate. Because the persons who reenter treatment are different from the persons who come for the first time, the authors do not believe that increasing the duration of treatment by adding a weaker intensity aftercare after a more intensive episode of care should be helpful for everyone. On the contrary, because the clinical profile of the persons worsens with the number of episodes of treatment, these authors recommend developing specific treatment adjusted to the greater needs of those who

The results of the study also raise an interesting issue: Do some individuals seek treatment for the first time with a severe profile and reenter treatment because the usual treatment was not appropriate for them or does the severity profile change over time (since these individuals did not solve their addiction, the related problems increase, and they come back with a more severe profile each time)? Future research using longitudinal methodology should be conducted to answer this question. 
In sum, this study provides empirical data useful to learn (or confirm) about the clinical profile of the persons who reenter treatment. The results offer an opportunity to conduct an interesting discussion with clinicians, treatment providers or other colleagues concerned by treatment modalities.

\section{References}

1 Simoneau H, Brochu S (2017) Addiction severity index profile of persons who reenter treatment for substance use disorders. Subst Abus 19: 1-6. 